\title{
GAIA Level 3b Postnatally Diagnosed Congenital Microcephaly
}

National Cancer Institute

\section{Source}

National Cancer Institute. GAlA Level 3b Postnatally Diagnosed Congenital Microcephaly. NCI Thesaurus. Code C128760.

GAIA Level 3b Postnatally Diagnosed Congenital Microcephaly is defined by two criteria: first, a live birth, stillbirth, or spontaneous or therapeutic abortion, and second, the case meets criteria for microcephaly using a validated algorithm: 1 inpatient diagnosis OR 2 outpatient diagnoses OR 1 outpatient diagnosis AND death in first year using the following diagnostic codes ICD-9-CM code 742.1 or ICD-10-CM code Q02. 